\title{
Professor-designer de experiências de aprendizagem na Educação Infantil: trabalhando a linguagem escrita e o/no contexto socioambiental dos alunos Teacher-designer of learning experiences in early childhood education: working the written language and the socio-environmental context of students
}

\author{
Bianca Martins, Melissa Oliveira \& André Cotelli
}

professor-designer, educação infantil, linguagem escrita, educação ambiental, jogos educacionais digitais.

\begin{abstract}
Este projeto articula o uso de procedimentos do Design em práticas educativas. Neste caso trabalhamos, particularmente, a concepção do professor como um designer de experiências de aprendizagem (PDEA). São apresentadas bases norteadoras deste conceito e sua relevância para a prática docente contemporânea. Descreve-se, então, como foi implementada uma ação pedagógica na Educação Infantil (EI) orientada pelo conceito PDEA. Aborda, também, questões que permeiam o trabalho pedagógico com a linguagem escrita na El. O interesse pelo tema surgiu da imbricação de expertises das autoras, a saber, design, tecnologia e docência na El. Partiu, ainda, do desafio de trabalhar a escritura na pré-escola como uma atividade relevante para a vida, como forma nova e complexa de linguagem. Objetivou-se, construir e avaliar uma proposta de ação do professor designer de experiências de aprendizagem no âmbito da El tendo como eixo condutor as funções sociais da escrita. A partir de procedimentos metodológicos do Design que valorizam o contexto e experiências dos sujeitos envolvidos no projeto, a pesquisa considerou os saberes dos participantes acerca do manguezal, bem como a sua preferência por Jogos Educacionais Digitais (JEDs). A pesquisa relata o processo de desenvolvimento e as características do JED. Apresentase a avaliação do mesmo por professores da Rede Pública do RJ. Os resultados produzidos evidenciam a (re)formulação de hipóteses e saberes relacionados às funções sociais da escrita no contexto socioambiental dos participantes e que o JED apresenta potencial para apoiar o trabalho pedagógico com essa modalidade de linguagem em diferentes espaços de EI no Brasil.
\end{abstract}

teacher-designer, early childhood education, written language, environmental education, digital educational games.

This project articulates the use of Design procedures in educational practices. In this case we work concepting the teacher as a designer of learning experiences (TDLE). Guiding bases of this concept and its relevance to contemporary teaching practice are presented. Then, we describe how a pedagogical action was implemented in Early Childhood Education (ECE) guided by the PDEA concept. It also dicusses the pedagogical work with the written language in ECE. Interest in the subject arose from the combination of the authors' expertise in design, technology and teaching at ECE. It also started with the challenge of working with preschool writing as a relevant activity for life, as a new and complex form of language. The objective was to construct and evaluate a proposal of action of the TDLE in the scope of ECE with the social functions of writing as its driving axis. From design methodological procedures that value the context and experiences of the subjects involved in the project, the research considered the participants' knowledge about the 'Manguezal', as well as their preference for Digital Educational Games (DEGs). The research reports the development process and characteristics of this DEG. The evaluation of this game by teachers of the Public Schools of RJ was presented. The results show the (re)formulation of hypotheses and knowledge related to the social functions of writing in the socio-environmental context of the participants and that the DEG has the potential to support the pedagogical work with this language modality in different spaces of EDE in Brazil.

\section{Introdução: O Professor-Designer de Experiências de Aprendizagem - PDEA}

Conforme Zaballa (2010), a aprendizagem de um novo fenômeno ocorre a partir da mobilização de competências em três dimensões: cognitiva (conhecimentos), procedimental (estratégias, tecnologias, mídias, metodologias, pedagogias, didáticas) e afetiva (comportamentos e relacionamentos). No cenário educativo contemporâneo a ubiquidade amplia a possibilidade do

Anais do 9 CIDI e 9 CONGIC

Luciane Maria Fadel, Carla Spinillo, Anderson Horta, Cristina Portugal (orgs.)

Sociedade Brasileira de Design da Informação - SBDI

Belo Horizonte | Brasil | 2019

ISBN 978-85-212-1728-2
Proceedings of the 9th CIDI and 9th CONGIC

Luciane Maria Fadel, Carla Spinillo, Anderson Horta,

Cristina Portugal (orgs.)

Sociedade Brasileira de Design da Informação - SBDI

Belo Horizonte | Brazil | 2019

ISBN 978-85-212-1728-2 
uso de recursos tecnológicos híbridos para mobilizar estas competências de formas inovadoras aumentando, assim, a chance de fazer sentido, motivar e instigar a atenção de estudantes de perfis muito variados (Martins, 2015). Ou seja, não importa somente o quê se deve aprender (dimensão cognitiva). A partir do uso de diferentes recursos didáticos (procedimentos) inseridos em diferentes estratégias pedagógicas, um planejamento docente cuidadoso possibilita dinamizar a mesma informação de maneiras diversificadas. Isso quer dizer que alunos diferentes, a partir de usos e interações diversificados, tem a chance de aprender conforme um estilo de aprendizagem que Ihe seja mais atraente/conveniente - dimensão afetiva (Mattar, 2010, p. 6). Logo, o contexto contemporâneo da aprendizagem requer que professores e gestores de educação, desempenhem com afinco a tarefa de identificar e empreender situações educativas levando em consideração os perfis dos estudantes.

Além do cuidado de levar em consideração os diferentes estilos de aprendizagem, o contexto educacional contemporâneo (Moraes, 2015; Martins. 2015, 2016), apresenta ainda outras características como: estudantes entendidos como sujeitos singulares, ênfase à reflexão na ação, autonomia, interação e colaboração; valorização da dimensão flexível e prática do currículo; ênfase em considerar a comunidade/contexto ao redor da escola como possível fonte de estratégias da aprendizagem; aprendizagem baseada em problemas; dentre outros. Vale a pena destacar neste cenário o papel de pesquisador ativo desempenhado pelo professor como sendo aquele sujeito que identifica necessidades e desejos dos seus estudantes para então selecionar e desenvolver situações didáticas instigantes e apropriadas (Martins. 2015, 2016, 2017).

Ao analisar este cenário educativo contemporâneo, Martins (2015) identificou que o nível de compreensão e apropriação dos fenômenos está relacionado à qualidade da interação entre o estudante e os recursos e/ou situações didáticas. Para que isso aconteça de forma proveitosa, o estudante precisa ter a oportunidade de interagir com objetos, refletir a respeito dos resultados obtidos e ser desafiado com situações novas e multidimensionalmente planejadas. Neste aspecto, Piaget (1978) argumenta que existe uma relação de solidariedade entre o sujeito e o objeto: o sujeito aprende a se conhecer mediante a ação sobre os objetos e os objetos se tornam cognoscíveis em função do progresso das ações do sujeito sobre eles. Ou seja: não é apenas fazer algo para chegar a uma resposta. A prática educativa precisa valorizar a interação com o que está sendo feito. Por isso os recursos e atividades precisam ser estimulantes, com linguagens ricas e oportunas, possibilitar aberturas para o professor introduzir desafios incrementando a qualidade da interação e envolvendo o estudante (Martins. 2015, 2016, 2017).

Todavia, este relacionamento entre o estudante e os objetos trabalhados não pode ser visto de forma separada de suas motivações mais profundas, seus desejos, suas projeções pessoais, suas identificações, sua memória etc. Isso quer dizer que, ao planejar o trabalho com os objetos e atividades didáticas, é necessário que o professor lance mão de estratégias que dialoguem com os desejos e vontades do estudante, o que implica no reconhecimento de afetos nem sempre identificáveis no cotidiano, mas que emergem durante a construção do conhecimento (Ardoino, 1998; Martins, 2017).

O contexto educativo esboçado leva-nos, ainda, ao pressuposto de que as aprendizagens ativas - situações onde é necessário desenvolver atividades práticas, projetos ou protótipos que articulem conhecimentos de diferentes dimensões da aprendizagem - podem ser usadas como recurso pedagógico que contribui para incrementar a qualidade da interação envolvendo o estudante (Martins. 2015, 2016, 2017). As aprendizagens ativas imbricam a dimensão de que o professor também precisa atuar como um ágil pesquisador identificando necessidades e desejos dos seus estudantes.

Atuando como um articulador destes aspectos - sujeitos, ações, recursos e contextos - a prática docente contemporânea em muito se assemelha ao processo projetual do Design. Por conta disso concebemos este profissional como um professor-designer de experiências de aprendizagem - PDEA. Percebido desta maneira o professor é um sujeito que planeja situações didáticas pesquisando e/ou fazendo a curadoria, sugerindo melhores práticas, ou até mesmo 
sendo autor/desenvolvedor das tecnologias mais apropriadas para seu público e contexto de uso (Martins, 2016, 2017, 2018). O PDEA desempenha uma ação pedagógica que tem como premissa epistemológica, política e metodológica que o sentir, o ser, o fazer e o pensar não se separam (Alves, 2003).

A concepção do PDEA imbrica e favorece sua atuação como um articulador das múltiplas dimensões do cotidiano escolar. Por isso, em sua prática docente, o PDEA considera as dimensões: 1) estudantes (seus conflitos, subjetividades e saberes); 2) meio (sala de aula, espaços, mobiliário, materiais e insumos, recursos tecnológicos etc.); e 3) conhecimento como ingredientes a conjugar nessa proposta de ação. Isso significa que a perspectiva do professordesigner de experiências de aprendizagem contribui para qualificar a docência, pois esta coloca o professor em evidência como um articulador da complexidade de saberes, valores, sentimentos e modos de interação de cada espaçotempo social (Alves, 2003; Martins, 2016; 2017).

Nos últimos 2 anos vimos desenvolvendo pesquisas junto a docentes do Ensino Fundamental e Médio com a intenção de compreender oportunidades de usos do Design no contexto escolar. Estas pesquisas e intervenções estão, particularmente, embasadas na concepção do professor-designer de experiências de aprendizagem. O caso ora relatado é uma pesquisa-intervenção realizada durante o Mestrado de Oliveira sob a orientação de Martins que teve como campo uma Escola Pública do Rio de Janeiro. Oliveira é professora da Educação Infantil desta escola e realizou a pesquisa junto a sua turma.

\section{PDEA no contexto da Educação Infantil: uma proposta de trabalho das funções sociais da escrita}

Levando em consideração o conceito de PDEA esta pesquisa desenvolveu-se no campo da Educação Infantil (El) visando lançar luz e trazer propostas concretas de atuação em um cenário de polêmicas existentes entre professores e estudiosos da área no que diz respeito às práticas pedagógicas destinadas à pré-escola, principalmente àquelas voltadas para o trabalho com a linguagem escrita (Nunes, 2006; Rosa, Brandão, 2011; Cunha, 2016; Figueiredo, 2016; Silva, 2016; Araújo, 2017b).

A motivação veio da necessidade de desmistificar a equivocada dicotomia existente entre as atividades lúdicas e aquelas que trabalham a linguagem escrita - o que ocasiona a implementação de práticas pedagógicas que fragmentam as múltiplas linguagens infantis (gestual, plástica, verbal, dramática e musical) e negligenciam a importância de sua integração para o desenvolvimento global das crianças (Brasil, 2010; Marinho, 2016).

No contexto da El a ludicidade, frequentemente vista apenas do ponto de vista estético, é o eixo norteador do planejamento pedagógico docente, assim como as interações entre os alunos (BRASIL, 2010), de tal forma que as trocas discursivas, as brincadeiras e as diferentes possibilidades de expressão representam os eixos condutores das atividades propostas.

Também foi um fator motivador a constatação de Oliveira (2018), pesquisadora e professora da pré-escola na Escola Municipal Floripes Angladas Lucas (EMFAL), de que as crianças em fase pré-escolar demonstravam inúmeros saberes e significados relacionados ao seu contexto socioambiental que, por uma série de fatores, permaneciam excluídos das atividades realizadas pela Unidade de Ensino (UE). Tal fato suscitou o questionamento sobre a forma como as aulas poderiam oportunizar situações em que essas redes cotidianas de conhecimentos (Alves, 2001; 2003; 2005) fossem ampliadas. Ainda, questionava-se como a linguagem escrita poderia ser uma ferramenta auxiliadora nesse processo, tanto para conscientizar os alunos acerca dos problemas de sua realidade quanto para interferir ativamente na construção da mesma (Freire, 1967).

Nesse sentido, as práticas pedagógicas apresentadas buscaram reconhecer o aspecto político inerente ao ato educativo, a partir de atividades que concebem a escrita como uma ferramenta de intervenção na realidade, com funções sociais dinâmicas, vivas (Freire, 1967). 
Estas práticas pedagógicas reconhecem a importância da concepção transformadora da linguagem, tendo em vista que não se pode pensar a elaboração cognitiva da escrita independentemente da sua função, do seu funcionamento, da sua constituição e da sua constitutividade na interação social uma vez que esse tipo de omissão neutraliza e oculta diferenças, provoca (e oculta) um conflito não meramente cognitivo, mas fundamentalmente social (Smolka, 2017, p.81).

Assim, em detrimento de práticas que negam a linguagem escrita ou que a apresentam de forma descontextualizada, visando a consolidação da alfabetização e o "preparo" do aluno ao Ensino Fundamental (BRANDÃO, ROSA, 2011), tivemos a intenção de enaltecer vivências trazidas do cotidiano, reiterando o importante papel da linguagem oral e dos momentos de interlocução durante o planejamento metodológico direcionado aos participantes (ALVES, 2003, SMOLKA, 2017; GOULART, 2014; CORSINO, 2011; SAVIAN, OMETTO, 2016). Oralidade e escrita foram considerados fatores indissociáveis e fundamentais para a aproximação entre os sujeitos e a cultura escrita ao passo que se entrelaçam e se influenciam mutuamente (GOULART, 2010 apud BRASIL, 2016).

O trabalho pedagógico com a linguagem escrita foi concebido nesta intervenção como uma sucessão de momentos discursivos (Smolka, 2017, p. 36) que visaram a valorização dos sujeitos e seus discursos (Baptista, 2010; Corais, 2015) e entenderam que os conhecimentos prévios infantis a respeito da linguagem escrita estão intrinsecamente relacionados às necessidades e às demandas desses indivíduos em seu contexto (Nogueira, Bueno, Nóbrega, 2015).

Compreendeu-se que dentre as condições essenciais para a ocorrência do processo de alfabetização estão a disponibilidade de materiais de leitura diversificados e o envolvimento, desde bem cedo, em atividades de contato e utilização de gêneros discursivos, mesmo antes do início do processo de sistematização da linguagem escrita pela criança (Brasil, 2016). E, ainda, que o contato com materiais escritos desde a infância constitui-se como uma das variáveis mais importantes para alcançar os níveis mais altos de alfabetismo na idade adulta e que as desigualdades existentes no contexto brasileiro podem ser ainda mais acirradas diante da relação (ou não) entre os indivíduos e a linguagem escrita na infância (Brasil, 2016; Cunha, 2016).

A Educação Infantil foi concebida, portanto, como uma etapa propícia para o convívio lúdico com diferentes suportes e gêneros orais e escritos, que podem ser abordados, dentre outras formas, a partir de brincadeiras e jogos que instigam a observação e a produção de textos pelos alunos que circulam em seu ambiente familiar, comunitário e escolar (Brasil, 2016).

Portanto, a proposta de intervenção e, mais especificamente, a proposição de um Jogo Educacional Digital (JED) que será descrito mais adiante, teve como premissa básica valorizar as redes cotidianas de conhecimentos dos alunos e suas linguagens. Ou seja, a partir da concepção do professor-designer de experiências de aprendizagem - PDEA - acredita-se que é preciso valorizar os conhecimentos já trazidos pelos sujeitos e, então, a partir daí, propor caminhos pedagógicos que contemplem o trabalho com a linguagem escrita na pré-escola com a intenção de promover a apropriação das funções sociais que a linguagem escrita pode desempenhar dentro do contexto socioambiental dos alunos. Desta forma explicita-se a articulação das dimensões sujeitos, ações, recursos e contextos no contexto do PDEA.

\section{PDEA: O contexto socioambiental como impulsionador das atividades pedagógicas}

Como já é sabido esta proposta de intervenção resultou em um JED para o trabalhar as funções sociais da escrita com alunos da El em uma Escola Municipal situada na Zona Oeste da cidade do Rio de Janeiro, mais especificamente, no bairro de Barra de Guaratiba. 
Figura 1: Fachada atual da EMFAL. Fonte: Silva (2018)

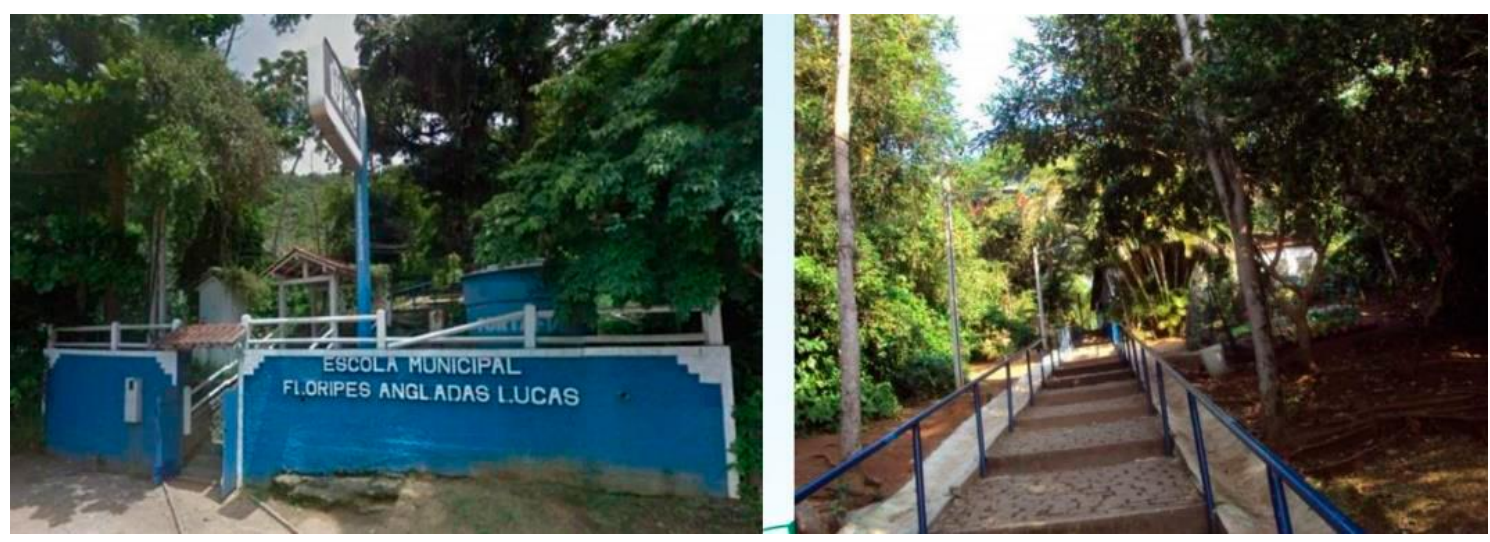

O corpo discente da escola, composto por crianças entre 4 e 10 anos de idade, habita seus arredores. Sua localização (FIGURA 3) é privilegiada por três amplos ecossistemas: o Manguezal, situado na parte superior esquerda da figura, a Restinga, na parte inferior esquerda, e a Mata Atlântica, localizada do lado direito do mapa. Ambos proporcionam as mais variadas formas de vida, tanto vegetais, quanto animais e compõem áreas de preservação ambiental, como a Reserva Biológica Estadual de Guaratiba (RBG) e o Parque Natural Municipal de Grumari.

De acordo com Castro et al. (2012), a RBG possui um ecossistema de mangue integrado às zonas de transição entre o manguezal e a terra firme, contendo espécies de vegetação que correspondem a áreas de restinga. Estudos realizados confirmaram que ambos os ecossistemas que se interligam e se relacionam na formação de um ambiente rico em fauna e flora.

Figura 2: Localização da EMFAL. Fonte:<https://www.google.com.br/maps/>. Acesso em: 14/08/18.

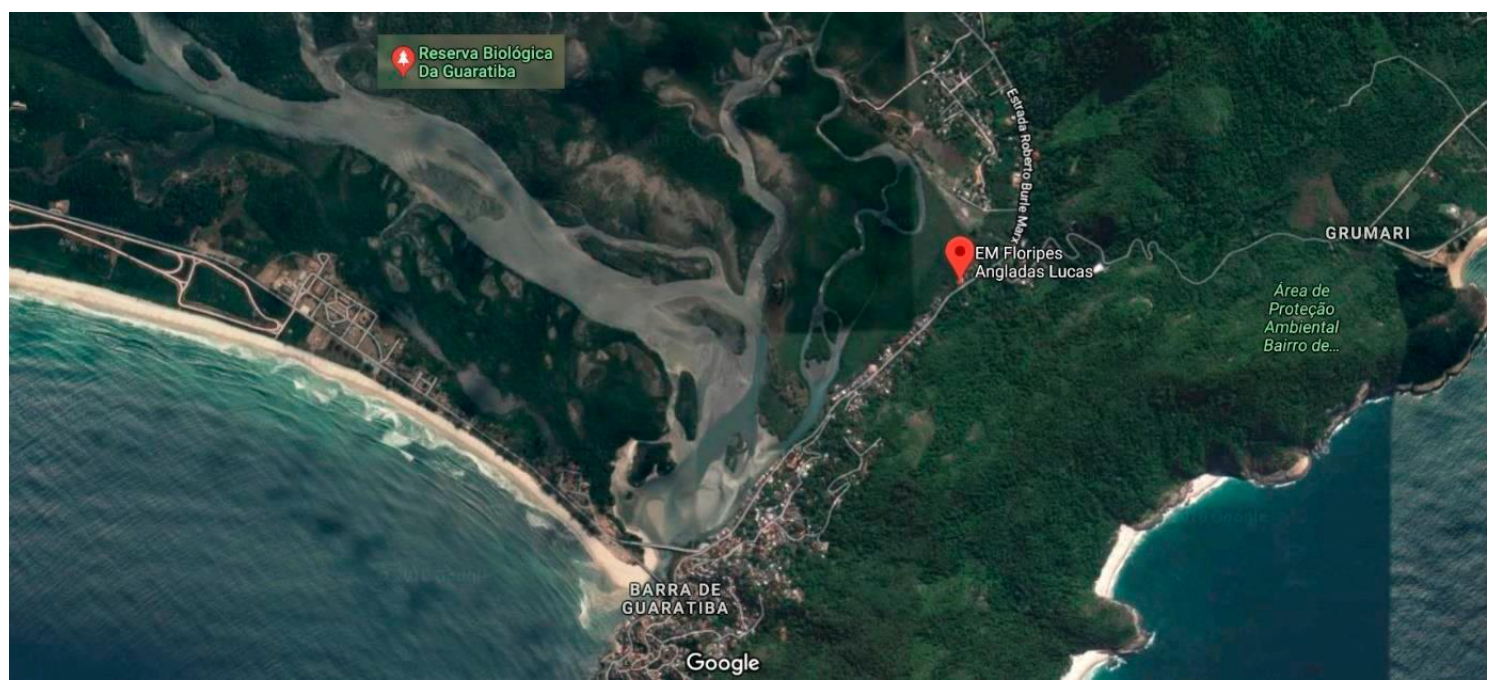

A degradação ambiental desse ecossistema pôde ser facilmente observada no bairro e afeta diretamente não só seu equilíbrio natural, mas também as famílias que dependem de seus recursos naturais para sobrevivência - como é o caso dos pescadores e catadores de caranguejos.

Devido às condições socioambientais do contexto da Escola e dando ênfase aos pressupostos do PDEA de articulação das dimensões sujeitos, ações, recursos e contextos na ação pedagógica, o estudo buscou implementar propostas pedagógicas que instigassem os 
Martins, B., Oliveira, M., \& Cotelli, A. | Professor-designer de experiências de aprendizagem na Educação Infantil: trabalhando a linguagem escrita e o/no contexto socioambiental dos alunos

alunos a interferir nessa realidade, utilizando a escrita como uma forma de linguagem capaz de auxiliar nesse processo.

\section{PDEA: o desenvolvimento de um Jogo Educacional Digital - JEDs para trabalhar as funções sociais da escrita na El}

\section{Diretrizes do Design}

Considerou-se partir das vivências e dos interesses das crianças (Brasil, 2016) que o incentivo às práticas de leitura é algo fundamental, mesmo diante de situações em que estas possuem poucas oportunidades de contato com a cultura escrita em seu cotidiano. Não obstante, os diferentes tipos de textos também se encontram onipresentes em tecnologias digitais. Estas, por sua vez, já invadiram os ambientes familiares e escolares e estão materializadas em diversos objetos (televisores, computadores, tablets, celulares etc.). Por isso, partiu-se do pressuposto de que o desenvolvimento de pesquisas visando discutir o potencial das mesmas para ressignificar práticas pedagógicas pautadas na apropriação da linguagem escrita é desejável e pertinente.

Uma vez que o conceito de PDEA também leva em consideração o uso do processo projetual do Design, a intervenção docente, apropriando-se das premissas deste processo, precisou os ouvir os sujeitos da pesquisa para conhecer seus desejos e necessidades em relação aos recursos e mediações para o trabalho com a cultura escrita. Para tal, optou-se metodologicamente pela realização de rodas de conversa com os alunos, donde pode-se apurar a motivação para o uso dos artefatos digitais. Estes foram apontados pelas crianças como algo muito legal, que poderia ter na aula da escola.

O Jogo Educacional Digital (JED) Amigos do Manguezal foi concebido durante a pesquisa e desenvolvido pela equipe do NUCAP/UniCarioca como será visto adiante.

Para a criação deste JED levou-se em consideração tanto a preferência das crianças por jogos digitais, quanto o caráter lúdico, prazeroso e motivador pertencente a estas ferramentas (Aragão; Nez, 2010). Contudo, ao refletir a respeito do desenvolvimento de softwares educacionais, Anacleto (2008) chama a atenção para a necessidade de aproximação entre os conteúdos didáticos trabalhados e as vivências trazidas pelos discentes. Por isso, e alinhado ao conceito do PDEA, o jogo articula-se às características de seus sujeitos praticantes, estando em consonância com quem eles são, o que gostam, o modo como aprendem e os conhecimentos que consideram significativos no contexto em que vivem (Alves, 2003).

Nesse sentido, o JED Amigos do Manguezal também viabiliza a customização de alguns de seus elementos pelo professor, de modo que este tenha autonomia de criar diferentes versões do mesmo, adequando-o aos interesses e aos conhecimentos já trazidos pela sua turma e, assim, favorecendo um trabalho mais aproximado ao cotidiano de seus sujeitos praticantes.

Figura 3: Utilização de JEDs por alunos da Educação Infantil da EMFAL. Fonte: Silva (2018)
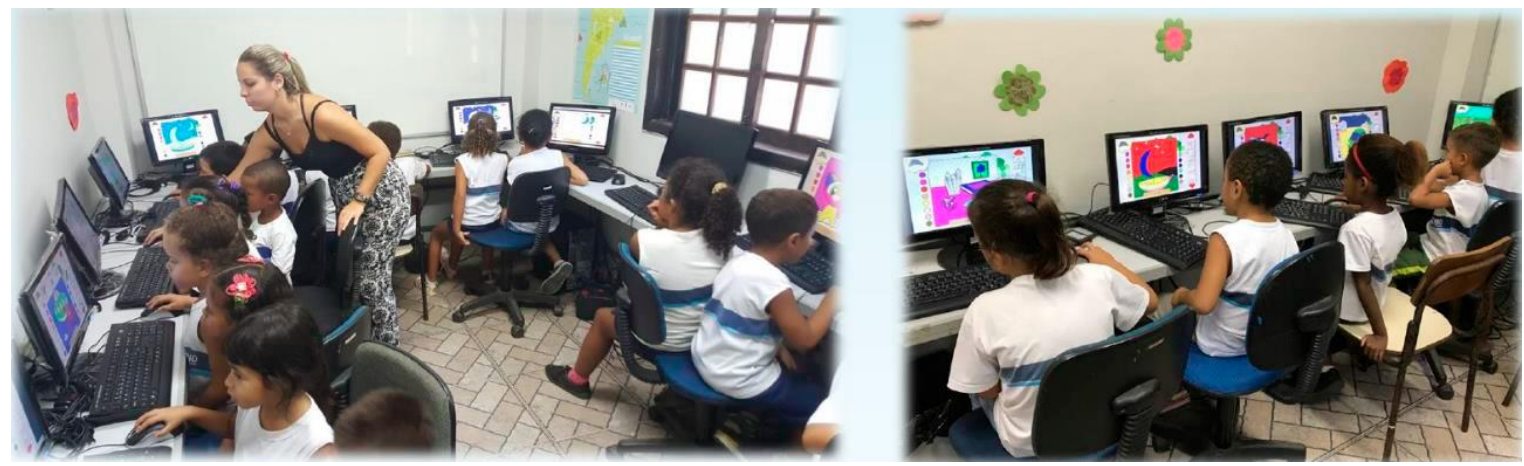

Anais do $9^{\circ}$ Congresso Nacional de Iniciação Científica em Design da Informação | CONGIC 2019

Proceedings of the $9^{\text {th }}$ Information Design Student Conference 
A escolha por um JED personalizável considerou, ainda, que a utilização de qualquer recurso pedagógico, seja ele digital ou não, deve ser realizada de forma sintonizada às experiências cotidianas dos alunos (Freire, 1967), o que, segundo Nilda Alves (2003), demanda, por parte dos professores regentes, uma imersão no contexto de seus alunos. $O$ JED desenvolvido nesse estudo, portanto, tem potencial para personalização de cenários e contextos socioambientais de turmas pertencentes à outras instituições de ensino.

Vale destacar que a possibilidade de personalização de cenários do jogo é justificada por aspectos políticos, sociais e contextuais. Em primeiro lugar, o ambiente que faz parte do cotidiano socioambiental dos estudantes precisa ser levado em consideração no planejamento pedagógico da instituição de ensino (Freire, 1967). Em segundo lugar, a problematização de situações socioculturais e ambientais onde as escolas estão localizadas e discussões a respeito da importância da preservação de ecossistemas e aspectos tradicionais da cultura regional, do qual intrinsecamente a comunidade escolar faz parte, precisam ser problematizados na escola. Situações de degradação são praticadas por moradores e comerciantes do bairro, através do corte de árvores e aterro para construção de casas, despejo ilegal de esgoto, descarte ilegal de lixo, desrespeito ao tempo de desova dos animais, entre outras ações.

Em consonância ao viés intervencionista de uma ação docente com base no pressuposto do PDEA, partiu-se do pressuposto de que é premente promover diálogos acerca desses problemas em instituições de ensino situadas nas áreas próximas aos ecossistemas, visando a tomada de consciência e a sensibilização da comunidade escolar para as consequências ambientais e socioculturais decorrentes dessas práticas.

Figura 4: Alunos da EMFAL durante visita escolar à RBG - ecossistema do manguezal. Fonte: Silva (2018).

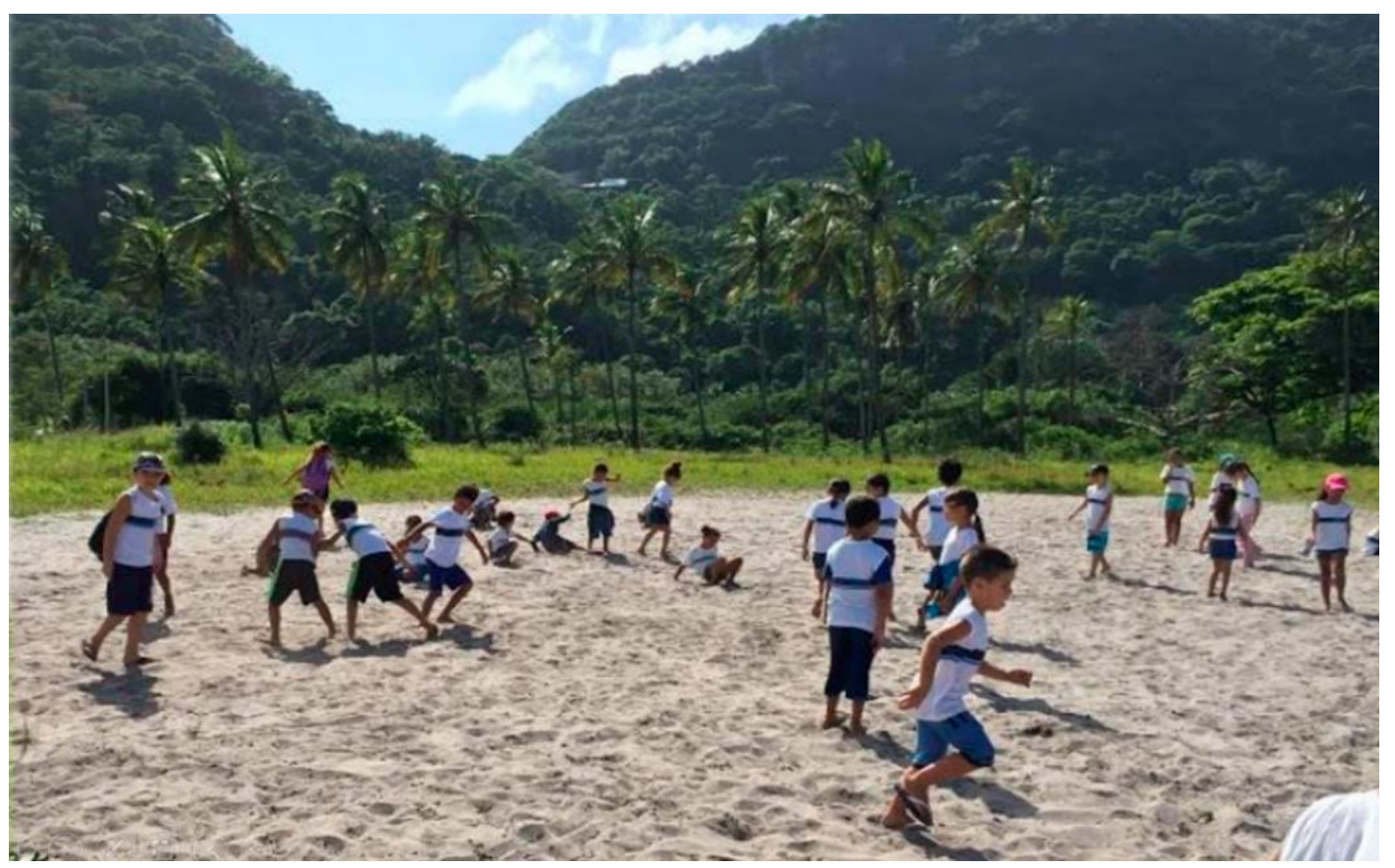

\section{Métodos}

\section{Desenvolvimento do protótipo Amigos do manguezal}

O protótipo foi produzido em parceria com o NUCAP/UniCarioca, a partir da engine Unity 3D por bolsistas de iniciação científica da instituição. O desenvolvimento do JED durou em torno de dez meses e ocorreu entre os anos de 2017 e 2018. A metodologia adotada envolveu três 
Martins, B., Oliveira, M., \& Cotelli, A. | Professor-designer de experiências de aprendizagem na Educação Infantil: trabalhando a linguagem escrita e o/no contexto socioambiental dos alunos

etapas: 1) Pesquisa exploratória; 2) Concepção; 3) Validação. Estas se encontram resumidas na Figura 3:

Figura 5: Metodologia proposta para o desenvolvimento do JED. Fonte: Autoras.

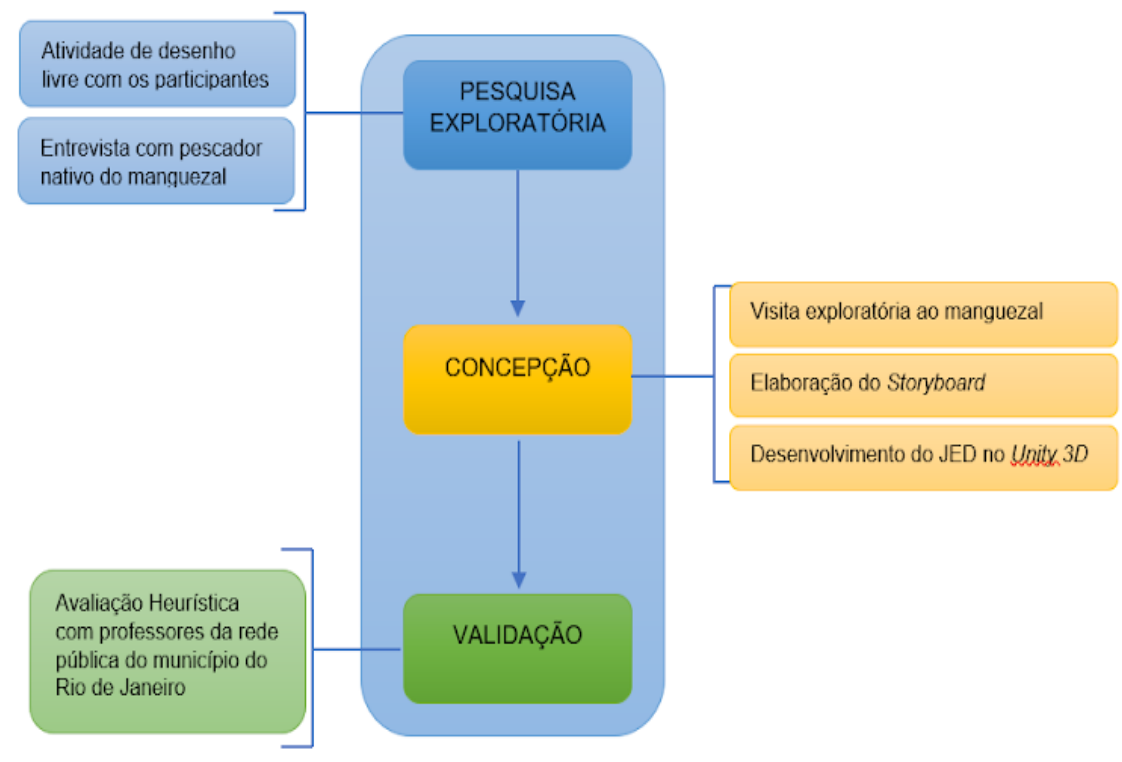

\section{Pesquisa exploratória}

A pesquisa exploratória teve dois momentos distintos: 1) com os participantes do estudo e 2) com um pescador nativo do manguezal da Reserva Biológica Estadual de Guaratiba.

Inicialmente, reuniu-se vinte alunos da pré-escola para uma atividade de desenho livre. Esta objetivou identificar o olhar dos participantes acerca de seu contexto socioambiental, bem como de possíveis recursos, interessantes e motivadores, que pudessem apoiar as atividades pedagógicas com a linguagem escrita. Assim, os alunos desenharam elementos de seu cotidiano de forma livre, com base em suas experiências e saberes. A atividade durou cerca de 40 minutos e foi realizada na sala de aula da turma.

No segundo momento, um pescador nativo do manguezal da Reserva Biológica Estadual de Guaratiba foi convidado para uma entrevista preliminar. Seu intuito foi ampliar os conhecimentos acerca do contexto socioambiental dos alunos, seu funcionamento e fatores que contribuem para a sua degradação. A entrevista durou cerca de 30 minutos.

Todos os dados coletados durante a pesquisa exploratória serviram de base para a etapa seguinte: a concepção do protótipo.

\section{Concepção do protótipo}

Durante esta etapa, visitas exploratórias ao manguezal da Barra de Guaratiba foram realizadas a fim de produzir dados fotográficos a serem incorporados ao protótipo. Além disso, esse contato direto com o ecossistema serviu de reflexão e surgimento de ideias para a dinâmica dos desafios enfrentados pelos jogadores, incorporando, ao mesmo tempo, o funcionamento do manguezal do ponto de vista biológico e seus elementos reais (fauna, flora etc.) à ludicidade no contexto da Educação Infantil. Com base nos dados produzidos, iniciou-se o

desenvolvimento do storyboard do Jogo. Estas foram as principais referências para a equipe de desenvolvimento durante a criação do cenário e da programação das funções do jogo. 
Figura 6: Manguezal da Barra de Guaratiba. Fonte: Autoras.

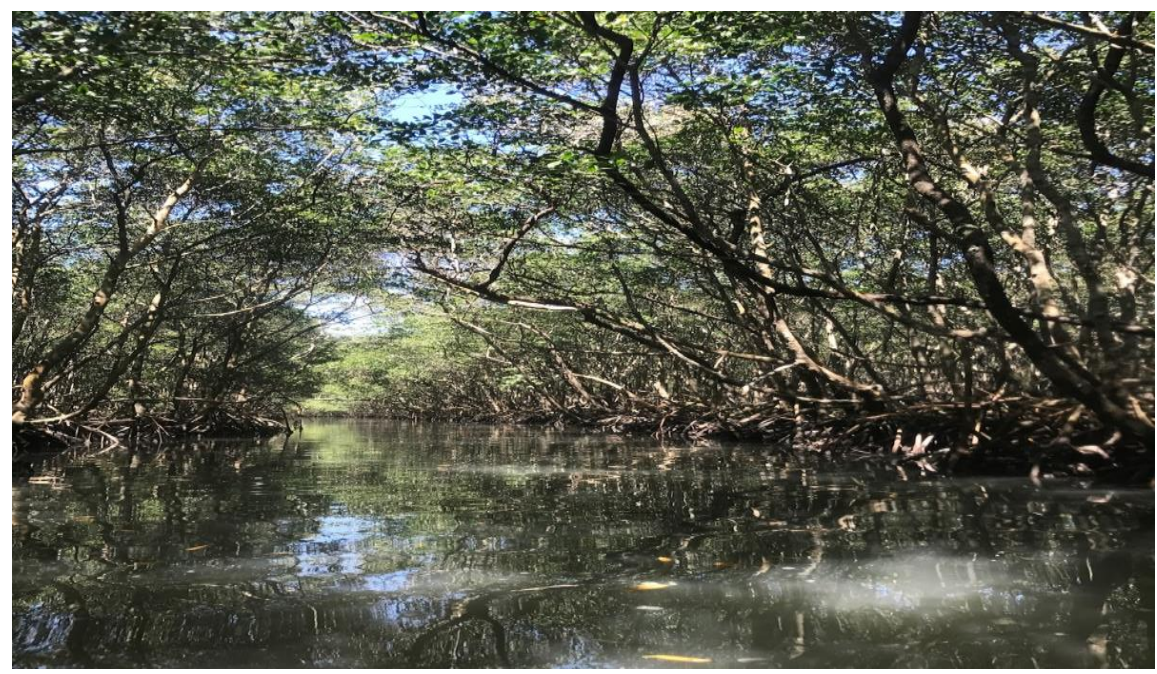

Com base nos direcionamentos presentes no storyboard, iniciou-se o desenvolvimento do referido JED através da Engine Unity $3 D$.

\section{Validação}

Para este estudo mostraremos a avaliação do JED por parte de uma equipe pedagógica que teve como objetivo analisar se o jogo estaria alinhado aos seus pressupostos pedagógicos e se estaria apto a ser inserido no ambiente educacional da El.

Aa Avaliação Heurística tem ganhado destaque na avaliação de softwares pois possibilita uma avaliação rápida, barata e eficiente, que pode ser realizada em qualquer fase de desenvolvimento dos mesmos (Valle, 2013).

Optou-se pelo método HEDEG (Heuristic Evaluation for Digital Educational Games) por ser direcionado especificamente aos JEDs. O HEDEG é dividido em cinco categorias: 1) Interface (elementos que permitem a comunicação entre os alunos e o ambiente do jogo); 2) Elementos Educacionais (permitem a construção de conhecimentos por parte dos alunos); 3) Conteúdo (elementos de conteúdo das disciplinas, que os alunos irão praticar no decorrer do jogo); 4) Jogabilidade (elementos relacionados à experiência do jogador, durante sua interação com o jogo); 5) Multimídia (elementos de multimídia do jogo, como por exemplo, sons, imagens, vídeos, entre outros) (Valle, 2013).

A aplicação das heurísticas foi realizada com doze professores que atuam na educação básica, em escolas pertencentes ao Município do Rio de Janeiro.

Discutiremos os resultados alcançados pela avaliação dos professores à luz dos conceitos do PDEA que conduzem este trabalho.

\section{Resultados}

\section{O Jogo Educacional Digital (JED) Amigos do Manguezal}

A narrativa do jogo baseou-se nos apontamentos feitos pelos alunos durante a pesquisa exploratória e nos eixos centrais para o trabalho pedagógico na Educação Infantil - as interações e a brincadeira (Brasil, 2010). Assim, o jogo digital lúdico foi produzido para ser 
Martins, B., Oliveira, M., \& Cotelli, A. | Professor-designer de experiências de aprendizagem na Educação Infantil: trabalhando a linguagem escrita e o/no contexto socioambiental dos alunos

jogado em dupla, possibilitando o revezamento entre os alunos para resolução dos desafios propostos.

Ao iniciar o jogo, o objetivo principal da dupla é resgatar pessoas e personagens que, cotidianamente, acabam se perdendo nos labirintos do manguezal, repleto de túneis de árvores com raízes aéreas. Para achá-los, eles devem, alternadamente, cumprir as missões que aparecem, interagindo com os animais da região, ajudando-Ihes a resolver os desafios ambientais do manguezal e, assim, somar medalhas.

Figura 7: Cenário do protótipo Amigos do manguezal. Fonte: Autoras.

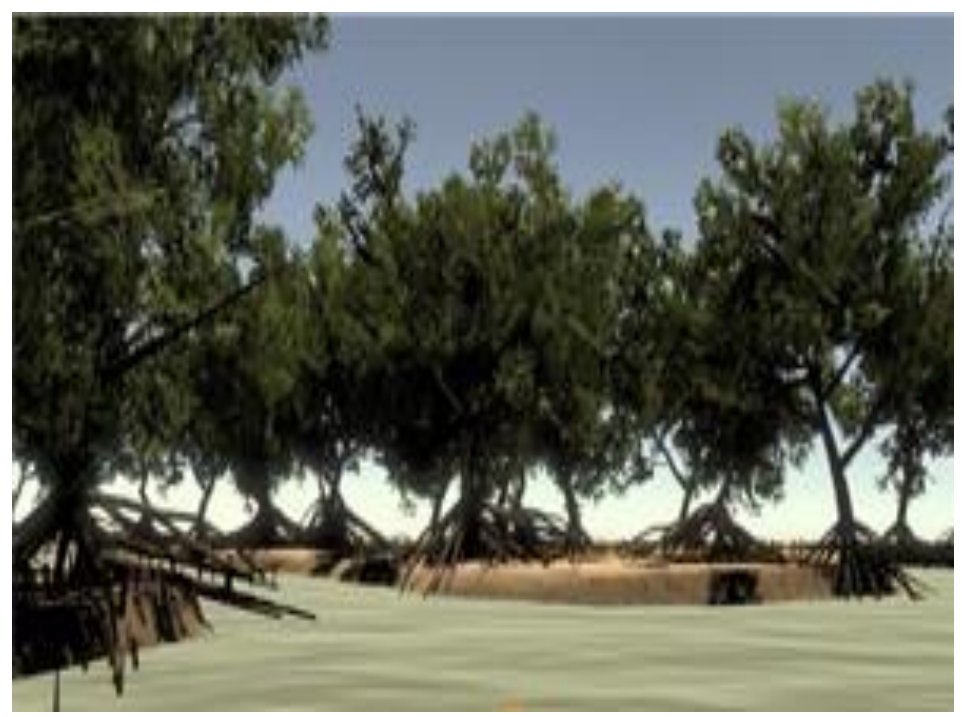

Além disso, os interesses e as preferências demonstradas pelas crianças durante a atividade de desenho livre também foram consideradas. A inclusão do labirinto, mencionado por um dos participantes em seu desenho, e o resgate de amiguinhos perdidos através dos canais do manguezal foram incluídos na narrativa. Durante esse resgate, jet skis são disponibilizados para o jogador ao longo da maré cheia.

Figura 8: Jet ski disponível para o jogador. Fonte: Autoras.

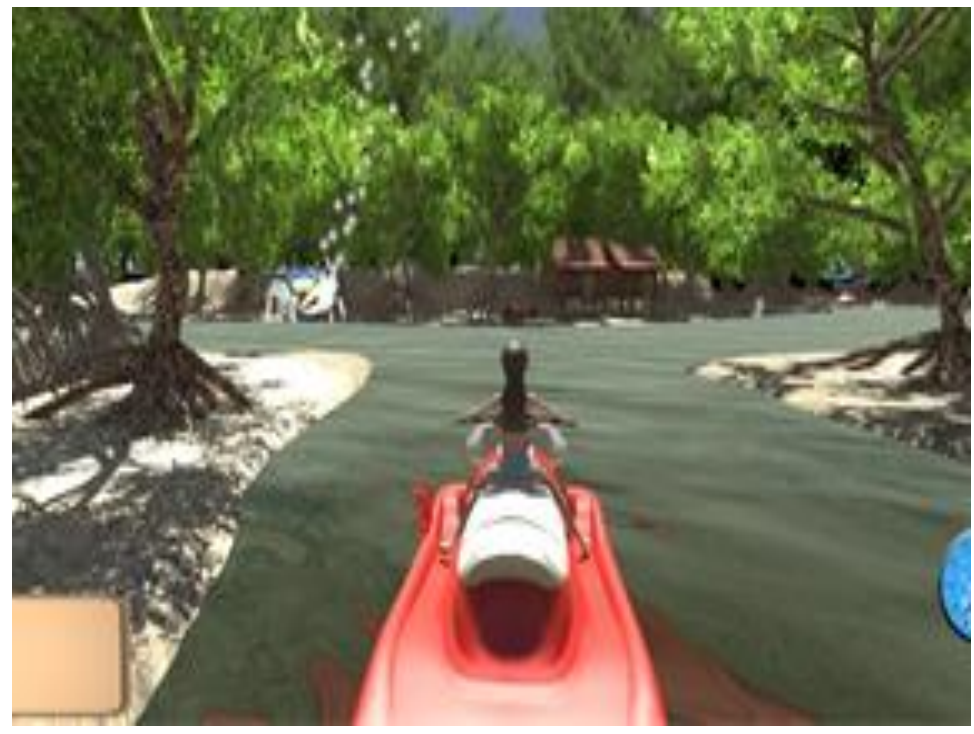

A entrevista preliminar realizada com o pescador também contribuiu para o desenvolvimento das funcionalidades do jogo. Além da inclusão da fauna, que pode ser personalizada pelo 
Martins, B., Oliveira, M., \& Cotelli, A. | Professor-designer de experiências de aprendizagem na Educação Infantil: trabalhando a linguagem escrita e o/no contexto socioambiental dos alunos

professor, houve também inclusão de missões, baseadas nos problemas ambientais relatados durante a entrevista. Assim, a resolução de cada missão exige que o jogador selecione o elemento que melhor se adeque à situação apresentada. Dentre eles, estão o jornal, o bilhete, a placa, a carta, a bula de remédio, o convite, o balão de grito, o balão de pensamento, o calendário e a receita.

Figura 9: Exemplo de missão. Fonte: Autoras.

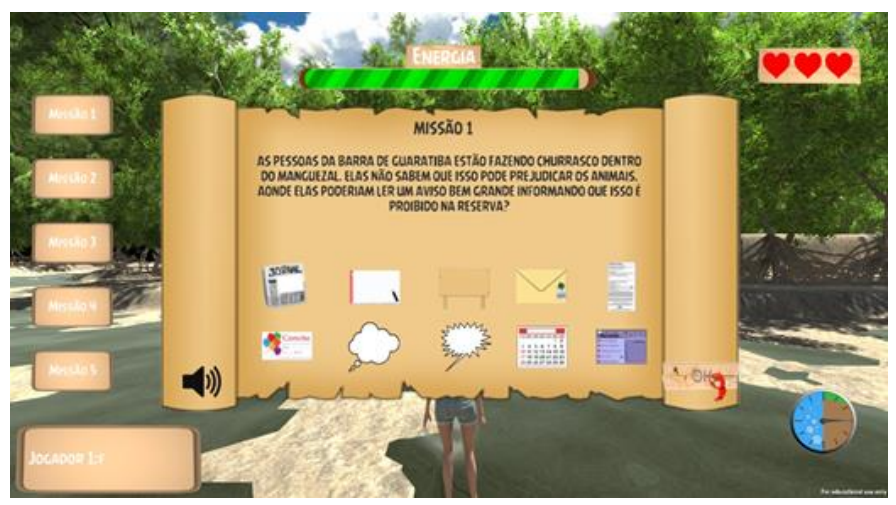

Após a seleção correta do elemento mais adequado à situação, o jogador segue seu percurso pelo cenário, procurando o animal que possui o mesmo. Ao encontrá-lo, abre-se uma tela destinada à escrita espontânea. Neste momento, não existe obrigação de que o jogador realize uma escrita alfabética. Ao contrário, este pode arriscar suas hipóteses sem medo de errar, pois não existe penalidade para erros ortográficos.

Figura 10: Tela destinada à escrita espontânea do jogador. Fonte: Autoras.

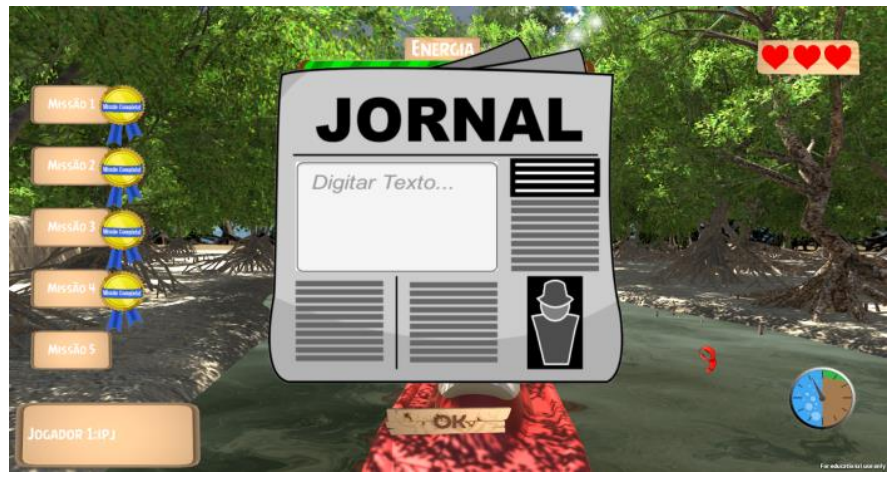

Após a resolução de todas as missões, os jogadores possuem medalhas suficientes para resgatar seu amigo perdido, tendo, assim, acesso ao local isolado onde o mesmo estava. Figura 11: Acesso ao local onde está o amiguinho perdido, após as missões concluídas. Fonte: Autoras.

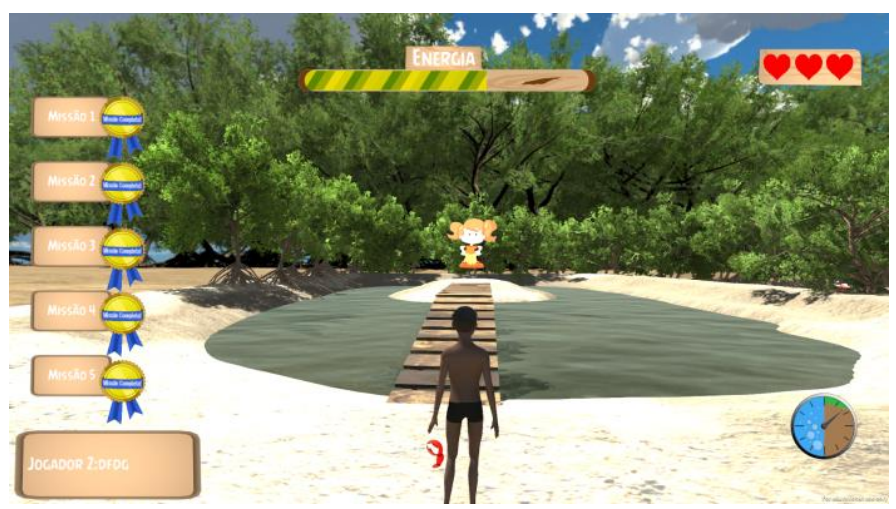


Martins, B., Oliveira, M., \& Cotelli, A. | Professor-designer de experiências de aprendizagem na Educação Infantil: trabalhando a linguagem escrita e o/no contexto socioambiental dos alunos

Por último, optou-se pela inclusão da linguagem escrita a partir de placas de aviso, que sinalizam ao jogador o momento em que este pode utilizar o jet ski. A mensagem vem acompanhada de um recurso sonoro, assim como as missões, a fim de que o jogador amplie seu potencial de atribuição de sentidos à linguagem escrita, presente no jogo.

Figura 12: Placa de aviso. Fonte: Autoras.

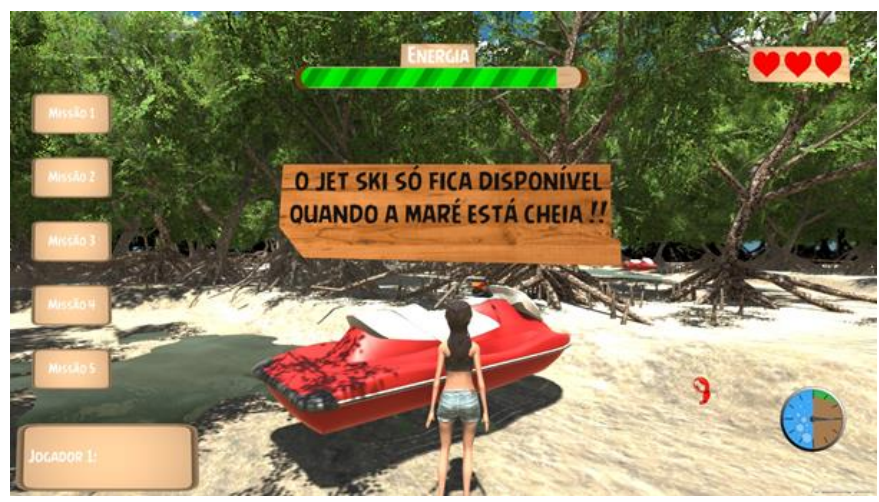

Ao final do jogo, todos podem festejar o tão esperado encontro, o manguezal continua preservado e os animais, felizes.

Figura 13: Tela final do jogo. Fonte: Autoras.

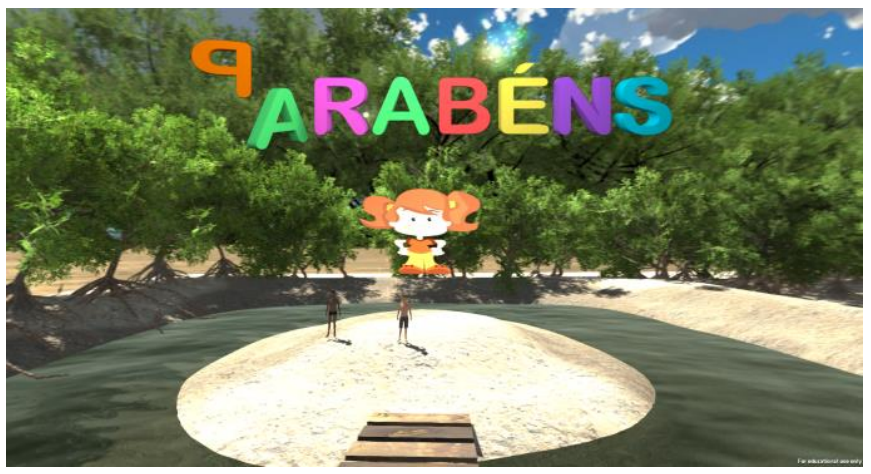

No menu inicial do JED é possível encontrar o botão Modo Professor, que possibilita a personalização de alguns elementos do jogo. Dentre eles, está o texto de cada missão, bem como o áudio correspondente à ele.

O JED também possibilita a customização de todos personagens presentes no cenário do jogo, com exceção do avatar. Os animais pertencentes a fauna do manguezal foram também oferecem a possibilidade de que desenhos dos próprios alunos sejam adicionados.

Figura 14: Modo Professor. Fonte: Autoras.

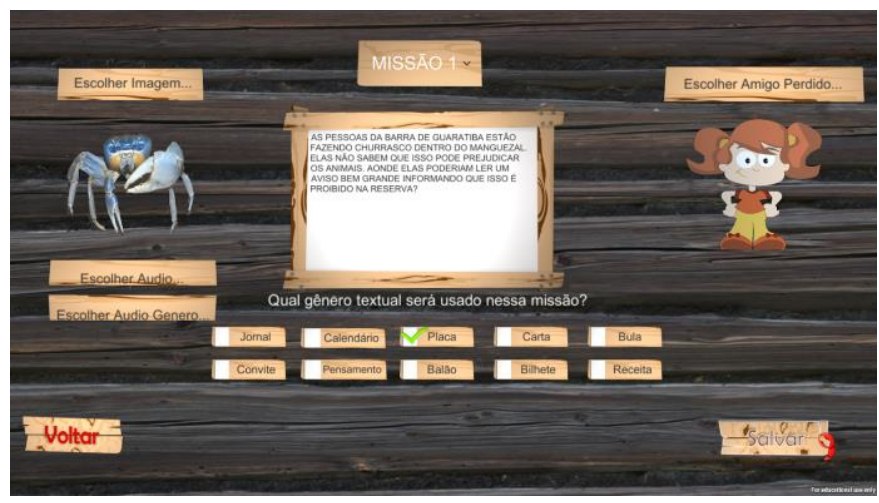


Martins, B., Oliveira, M., \& Cotelli, A. | Professor-designer de experiências de aprendizagem na Educação Infantil: trabalhando a linguagem escrita e o/no contexto socioambiental dos alunos

\section{Discussão}

A Avaliação Heurística foi realizada com doze professores do Município do Rio de Janeiro, todos atuantes em turmas de Educação Infantil e/ou do ciclo de alfabetização, sendo três da própria ENFAL e os demais atuantes outras escolas públicas do Município do RJ.

Foi realizada uma reunião presencial com todos os professores participantes com o objetivo de apresentar o contexto da pesquisa, bem como o protótipo do jogo. Nesta ocasião, os professores puderam tirar dúvidas e interagir com o JED. Ao final, todos receberam um link para um questionário envolvendo as heurísticas já apresentadas. Para cada heurística o participante poderia dar uma nota de 1 a 10, em que 1 significava Muito Ruim, e 10 significava Ótimo.

A seguir a avaliação de cada quesito discutidas à luz dos preceitos do PDEA:

Interface: o JED Amigos do Manguezal recebeu, na maioria dos casos, notas acima de sete. Levando em consideração os preceitos do PDEA podemos inferir que a interface do protótipo criado está em sintonia com os elementos do contexto da escola constituindo-se como uma atividade contextualizada com as experiências do cotidiano das crianças.

Elementos Educacionais: o JED recebeu notas acima de sete na maioria. Entendemos que o objeto e as práticas por ele desencadeadas oferecem satisfatória ludicidade e versatilidade em seus elementos educacionais. Vale destacar a capacidade de adaptação a diferentes informações e habilidades a serem aprendidas oferecidas por um jogo que pode ser personalizado.

Contudo, o JED recebeu também uma pequena frequência de notas seis ou abaixo disso em seus Elementos Educacionais, no que se refere às possibilidades de personalização de alguns itens. Para entender o que motivou tais professores a avaliar desta forma seria necessário realizar novas entrevistas aprofundando este tema.

Conteúdo Educacional do Jogo: Foram atribuídas notas predominantemente acima de oito. Entendemos, dentre outros aspectos, que a atividade é eficiente em garantir que os conteúdos pedagógicos sejam construídos de forma organizada, prazerosa e atrativa ao usuário.

Jogabilidade: $O$ JED recebeu notas acima de sete em oito das nove heurísticas existentes. Este aponta certa eficiência do jogo em garantir que o usuário não tenha dificuldades em jogar, sendo os comandos intuitivos, as recompensas satisfatórias e desafios não frustrantes para o usuário. Além disso, segundo eles, o jogo traz uma sensação de imersão, algo positivo para o engajamento do jogador.

Multimídia: O protótipo criado foi predominantemente avaliado com notas acima de nove em todas as heurísticas que tratam deste aspecto - sons, animações, imagens e textos. Isso evidencia, dentre outras coisas: satisfatória integração entre estes recursos e o conteúdo pedagógico; combinações consistentes entre os elementos de multimídia presentes no JED e boa qualidade/atratividade desses recursos.

\section{Considerações finais}

Conforme elaboramos ao longo do trabalho, um dos desafios da docência contemporânea é o que o professor atue como um articulador das diferentes instâncias da sua prática. Esta forma de atuação precisa levar em consideração os sujeitos implicados, os recursos didáticos, os contextos e as ações a serem desempenhadas. Ao desempenhar este papel professor contemporâneo lança mão de ações muito semelhantes ao processo projetual do Design. Por conta disso concebemos o profissional que atua desta forma como um professor-designer de experiências de aprendizagem - PDEA. 
Esta pesquisa teve como objetivo propor alternativas para o trabalho pedagógico com a linguagem escrita na pré-escola. A partir das propostas do PDEA a professora foi instigada a atuar como uma articuladora das múltiplas dimensões do cotidiano escolar: estudantes-meioconhecimento. Valorizando princípios do Design, considera-se que estas três dimensões não podem estar dissociadas. Isso quer dizer que o trabalho com a linguagem escrita aconteceu de forma sintonizada às outras dimensões. Assim, para atuar de forma proveitosa, a professora precisou, também, conhecer mais amiúde as subjetividades e saberes trazidos por seus alunos e explorar o contexto socioambiental da escola como eixo norteador das atividades propostas.

Ainda e conforme a concepção do PDEA, a aprendizagem de um novo fenômeno ocorre a partir da mobilização de competências nas dimensões (1)cognitiva, (2)procedimental e (3)afetiva. Por isso, a intervenção docente aqui esmiuçada aconteceu a partir de atividades prazerosas (3), mediatizadas por meio de um jogo (2) que ofereceram contato com diferentes gêneros escritos (1). A conjunção destas dimensões possibilitou a produção de percursos, narrativas e textos de forma lúdica e criativa pela criança.

Como vimos, o Jogo Digital Amigos do Manguezal foi avaliado por professores da Educação Básica que evidenciaram pontos positivos e fragilidades do mesmo. Dentre os positivos, destacaram-se, principalmente, seus recursos de multimídia e conteúdos educacionais. Por outro lado, dentre as fragilidades, foi possível identificar o modo multitarefas, os recursos de adaptabilidade e de escolha do nível de dificuldade do jogo. Nesse caso, pensamos ser necessário maior aprofundamento em ocasiões futuras.

Assim, é possível concluir que o JED Amigos do Manguezal, concebido a partir dos pressupostos do PDEA, tem potencial para apoiar o trabalho pedagógico com a linguagem escrita em diferentes espaços de Educação Infantil no Brasil, especialmente nas regiões de ocorrência do ecossistema Manguezal. O jogo também tem potencial para promover experiências de aprendizagem da linguagem escrita sem negligenciar os interesses, as vivências e as necessidades dos participantes. Além disso, pensamos que o jogo pode ser capaz de oportunizar experiências que promovam o envolvimento dos pequenos com o meio ambiente e a preservação da natureza, visando auxiliá-los na elaboração de saberes relacionados ao seu cotidiano.

Finalmente, espera-se que esta pesquisa contribua para que profissionais das áreas da Educação e do Design possam realizar novos estudos investigando potências da sinergia entre estas duas áreas para o cotidiano escolar. Particularmente, tem-se a esperança que novos professores sintam-se instigados a atuar como designers de aprendizagem.

\section{Referências}

Alves, N. (2001). Decifrando o pergaminho: o cotidiano das escolas nas lógicas das redes cotidianas. Pesquisa no/do cotidiano das escolas: sobre redes de saberes. Rio de Janeiro: DP\&A, p. 13-38.

Alves, N. (2003). Sobre movimentos das pesquisas nos/dos/com os cotidianos. Pesquisa nos/dos/com os cotidianos escolares: sobre redes de saberes. TEIAS: Rio de Janeiro, ano 4, no 7-8.

Alves, N. (2005). Redes Urbanas de Conhecimentos e Tecnologias na Escola. In: IntercomSociedade Brasileira de Estudos Interdisciplinares da Comunicação XXVIII Congresso Brasileiro de Ciências da Comunicação-Uerj-5 a. 2005.

Anacleto, J. C. et al. (2018). Ambiente para criação de jogos educacionais de adivinhação baseados em cartas contextualizadas. In: Anais do Workshop de Informática na Escola. 2008. Disponível em: < http://www.br-ie.org/pub/index.php/wie/article/viewFile/988/974> Acesso em: 10 fev. 2018. 
Martins, B., Oliveira, M., \& Cotelli, A. | Professor-designer de experiências de aprendizagem na Educação Infantil: trabalhando a linguagem escrita e o/no contexto socioambiental dos alunos

Aragão, D. S.; Nez, E. (2010). Jogos educativos com o uso do computador na Educação Infantil. SIMPÓSIO NACIONAL DE EDUCAÇÃO. 2010

Araujo, L. C. (2017a). Ler, Escrever E Brincar Na Educação Infantil: Uma Dicotomia Mal Colocada. Revista Contemporânea de Educação, v. 12, n. 24, p. 344-361, 2017 a.

Araújo, F. C.(2017b). A construção da escrita na Educação Infantil: uma análise na turma do nível V, da Escola Municipal Valdemir Fernandes de Medeiros, em Jucurutu-RN / Fayanne Carla de Araújo. - Caicó: UFRN, 2017b.

Ardoino, J. (1998). Abordagem Multirreferencial (plural) das situações educativas e formativas. In: BARBOSA, Joaquim (Coord.). Multirreferencialidade nas ciências e na educação. Trad. Rosângela B. de Camargo. São Carlos, SP: EdUFSCar, 1998. p. 24-41.

Baptista, M. C. (2010). A linguagem escrita e o direito à educação na primeira infância. In: Seminário Nacional: Currículo E Movimento, 1., 2010, Belo Horizonte. Anais. Belo Horizonte, Secretaria de Educação Básica, 2010.

Brandão, A. C. P., \& Rosa, E. C. S. (2011). Ler e escrever na Educação Infantil : discutindo práticas pedagógicas / Ana Carolina Perrusi Brandão, Ester Calland de Sousa Rosa, organização. - Belo Horizonte : Autêntica Editora, 2011.

Brandão, A. C. P., \& Silva, A. C. (2017). O ensino da leitura e escrita e o livro didático na Educação Infantil. Educação, vol. 40, núm. 3, septiembre-diciembre, 2017, pp. 440-449.

Brasil. Ministério da Educação. Secretaria de Educação Básica. (2010). Diretrizes curriculares nacionais para a educação infantil / Secretaria de Educação Básica. - Brasília : MEC, SEB, 2010.

Brasil. Ministério da Educação, Secretaria de Educação Básica. (2016). Linguagem oral e linguagem escrita na educação infantil: práticas e interações.1.ed. - Brasília : MEC /SEB, 2016.

Bresciane, A. L. (2004). Alfabetização e educação infantil: relações delicadas. Revista Avisa Lá, n. 17, p. 37-39, jan. 2004.

Castro, A. O. C., Gomes, A. A., Batista, G. V. C. P., \& Gonçalves, J. T. (2012). Os desafios do planejamento e conservação ambiental da Reserva Biológica de Guaratiba (RJ). Revista Nordestina de Ecoturismo, Aquidabã, v.5, n.1, p.69-76, 2012.

Corais, M. C. (2015). A linguagem na vida, na vida na linguagem! Afinal, qual a relação entre educação infantil e alfabetização. Goulart, Cecília. Como alfabetizar? Na roda com professores dos anos iniciais. Campinas, SP: Papirus, 2015.

Corsino, P. (2011). Professoras de educação infantil e suas visões de letramento: tensões da prática. In: Kramer, S.; Rocha, E. C. (Org.). Educação infantil: enfoques em diálogo. 3. ed. Campinas: Papirus, 2011.

Cunha, N. M. D. (2016). O lugar da linguagem escrita na vida das crianças da Educação Infantil. - Natal, RN, 2016.

Figueiredo, R. G. (2016). Leitura e escrita na educação infantil: reflexões sobre uma experiência no Colégio Pedro II. 2016.

Freire, P. (2017). Educação Como Prática da Liberdade, 1967. Rio de Janeiro: Paz e Terra. Disponível em: <http://www.dhnet.org.br/direitos/militantes/paulo freire/livro_freire_educacao_pratica_liberdade.pdf>. Acesso em: 20 jun. 2017.

Gomez, M. V. (2002). Alfabetização na Esfera Digital: Uma Proposta Freireana. Revista educação em foco. Juiz de Fora. Vol. 7, no 1, p 99-115. Mar/agosto de 2002

Goulart, C. (2014). O conceito de letramento em questão: por uma perspectiva discursiva da alfabetização. Bakhtiniana. Revista de Estudos do Discurso, v. 9, n. 2, p. 35-51/Eng. 40-56, 2014. 
Martins, B., Oliveira, M., \& Cotelli, A. | Professor-designer de experiências de aprendizagem na Educação Infantil: trabalhando a linguagem escrita e o/no contexto socioambiental dos alunos

Goulart, C. (2010). Cultura escrita e escola: letrar alfabetizando. In: Marinho, Marildes e Carvalho, Gilcinei Teodoro (Org.). Cultura escrita e letramento. Belo Horizonte, Editora UFMG, 2010, p.438-456.

Marinho, G. R. (2016). Ler e escrever na Educação Infantil: análise de uma proposta curricular. Veras, v. 6, n. 1, p. 87-104, 2016.

Mattar, J. (2010). Games em educação: como os nativos digitais aprendem. São Paulo: Pearson Prentice Hall, 2010. 181 p.

Martins, B., \& Couto, R. (2014a). Design instrucional como um diálogo interdisciplinar entre Design e Educação. In: Design em situações de Ensino-Aprendizagem. 1ed.Rio de Janeiro: Rio Books, 2014, v. , p. 45-.

Martins, B. Valle, F. B. ; Mirabeau, A. (2014b). Relato de planejamento da pedagogia do Design: planificação de projetos integradores e sua implementação didática. 2014. (Apresentação de Trabalho/Congresso).

Martins, B; Valle, F., Mirabeau, A, \& Caldi, L. (2015). Implantação da Aprendizagem Baseada em Projetos (ABP) em uma Graduação em Design Gráfico. 2015. (Apresentação de Trabalho/Congresso).

Martins, B., \& Couto, R. (2015). Aprendizagem Baseada em Design: uma pedagogia que fortalece os paradigmas da educação contemporânea In: Anais of the 7th CIDI 2015 [Blucher Design Proceedings, num. 2, vol.2]. São Paulo: Blucher, 2015.

Martins, B., Siqueira, A., Mol, A., Fernandes, S., \& Rocha, T. (2016). O uso de vídeos 3D em uma dinâmica moderna para atividades de ensino em diferentes espaços educativos: um estudo de caso no evento NUCAP de Portas abertas. In: Anais do SBGames. São Paulo: SBC, 2016. p. 1261-1263.

Martins, B., Roberto, M., Verde, D., Santos, J., Cotelli, A., Mol, A., \& Siqueira, A. (2017). Recursos digitais como motivação para a aprendizagem: vivência da exposição interativa Brincando com o sol. Revista Carioca de Ciência, Tecnologia e Educação, v. 2, p. 11-41, 2017.

Martins, B., Fernandes, S., Nóbrega, T., Lemos, N., Mol, A., \& Cotelli, A. (2017). Ressignificando o projeto sobre cultura indígena por meio das tecnologias digitais: a holografia como possibilidade na Educação Infantil. In: Anais do Simpósio: Sociedade Brasileira de Computação (SBC), 2017.

Nogueira, G. M., Bueno, L. A.; Nóbrega, T. F. R. (2015). Relações entre oralidade e escrita em uma situação de leitura de um livro de história em uma turma de educação infantil. TEXTURA-ULBRA, v. 17, n. 35, 2015.

Nunes, M. F. R. (2006). Educação Infantil: instituições, funções e propostas. In: CORSINO, Patrícia. O cotidiano na Educação Infantil. Programa Salto para o Futuro. Bol. 23, nov./2006.

Piaget, J. (1978). A formação do símbolo na criança: imitação, jogo e sonho, imagem e representação. 3ed. Rio de Janeiro: Zahar Editores, 1978.

Sampaio, C. S., Ribeiro, T., \& Venâncio, A. P. (2017). Alfabetização, currículo e formação com as crianças: reflexões a partir do cotidiano da escola. Revista Teias, v. 18, n. 50. 2017, p. 69-87.

Savian, M. R., \& Ometo, C. B. C. N. (2017). A Alfabetização Como Prática Dialógica De Leitura E Escrita. Revista Brasileira de Alfabetização, v. 1, n. 3, 2017.

Smolka, A. L. B. (2018). A criança na fase inicial da escrita. [livro eletrônico]: a alfabetização como processo discursivo. São Paulo: Cortez, 2017. Disponível em: <https://play.google.com/books/reader?id=uXMzDwAAQBAJ\& printsec=frontcover\&output=reader\&hl=pt_BR\&pg=GBS.PT2> Acesso em: 02 fev. 2018. 
Martins, B., Oliveira, M., \& Cotelli, A. | Professor-designer de experiências de aprendizagem na Educação Infantil: trabalhando a linguagem escrita e o/no contexto socioambiental dos alunos

Silva, Aline Araújo Caixeta da. (2016). A linguagem escrita na educação infantil: orientações, concepções e perspectivas. 2016.

Valle, P. H. D. et al. (2013). Hedeg-heurísticas para avaliação de jogos educacionais digitais. Nuevas Ideas en Informática Educativa TISE, 2013.

Zabala, A., \& Arnau, L. (2010). Como aprender e ensinar competências. Tradução de Carlos Henrique Lucas Lima. Porto Alegre: Artmed, 2010. 197 p. 